\title{
The Calculations of Ring Current of Some Benzenoids using Randić Model
}

\author{
Manal O. Hamzah* \\ *Department of chemistry, college of science of women, University of Baghdad, Jadriah, Baghdad, Iraq
}

*Corresponding Author: Manal O. Hamzah, Department of chemistry, college of science of women, University of Baghdad, Jadriah, Baghdad, Iraq

\begin{abstract}
The ring currents of some benzenoids were calculated using a graph theoretical model as called Randić. This model follows the first law of Kirchhoff. And it gives a qualitative visualization of currents expressive as plotted maps. The currents in the maps are decomposed into perimeter and interior bond currents. The results showed that the induced currents of bonds on perimeter of all molecules were diatropic (anticlockwise). And all the molecules were aromatic (diamagnetic). The numerical values indicated that the currents were affected by the shape and the size of molecules.
\end{abstract}

Keywords: currents, Randić, diatropic, conjugated circuits, catafusenes.

\section{INTRODUCTION}

The ring currents as described by Pauling ${ }^{1}$ and Lonsdale ${ }^{2}$, is a freedom of movement of electrons in $P_{\mathrm{z}}$ orbital of benzene and other aromatic hydrocarbons between adjacent carbon atoms. It is occurred in the presence of an external magnetic field to form interatomic $\pi$ currents above and below the molecular plane. ${ }^{1,2}$ It considered a prominent feature of aromatic compounds. Aromatic and antiaromatic systems can be distinguished according to their magnetic properties. ${ }^{3}$ Since an aromatic species have the ability to support a diatropic ring current (anticlockwise, opposed ring current circulation), but antiaromatic compounds support a paratropic ring currents (clockwise, aligned ring current circulation). ${ }^{4}$ Therelation between aromaticity and ring currents was proved by nuclear magnetic resonance spectroscopyNMR. ${ }^{5}$

Theoretically, the ring current was calculated using different methods such as conjugated circuits CC.A conjugated circuit CC model was introduced by Randić in early $2000 .{ }^{6}$ Randić ${ }^{7}$ assumed that the currents flow in the set of conjugated circuits which are defined as those circuits in Kekule valence structures $K$ (alternation of single and double bonds). The CC necessarily even, and they were counted as two perfect matching $K(K-1) / 2{ }^{5}$ The matchings are defined as a single conjugated circuits or a set of disjoint conjugated circuits. ${ }^{8}$

Randić model weighs all conjugated circuits (single and set of disjoint) that contributes to each bond as $\pm 2[m(G-C)]^{2}$, where the sign is determined by the orientation of conjugated circuit, $(+)$ for anticlockwise direction of $4 n+2$ cycles, (-) for clockwise direction of $4 n$ cycles and mis the perfect matching of conjugated circuit $C$ in the molecular graph $G .{ }^{8}$ Thismodel obeys Kirchhoff's first law thus the currents of two bonds with the same values and different directions are cancelled. ${ }^{9}$ Randic model gives a qualitative insight of ring current. Nevertheless it has a drawback that it has a lake of distinguish between the systems with similar geometry but different magnetic response such as benzene and borazine. ${ }^{8}$

In the present work, the ring currents of a set of benzenoids were calculated using CC model of Randić. The unnormalised values were plotted as maps and the normalised currents were listed.

\section{THE METHOD OF CALCULATION}

The set of molecules consists of 19 benzenoids. The molecules were classified according to their dualist graphs to catacondensed with no carbon atom common with three benzenoid rings, for which the dualist graphs are acyclic ${ }^{10,11}(\mathrm{KF} 1, \mathrm{KF} 2, \mathrm{KF} 3, \mathrm{KF} 4, \mathrm{KF} 5, \mathrm{KF} 6, \mathrm{KF} 7, \mathrm{KF} 10, \mathrm{KF} 13$ and KF15) and 
pericondensed which contain some carbon atoms common to three benzenoid rings and their dualist graphs include three membered rings ${ }^{12}$ such as (KF8, KF9 and KF17).The set of molecules was chosen because it considers a good source of different size and shape of benzenoids. ${ }^{13}$

The benzenoids were drawn using Chem Draw (Ultra 10). ${ }^{14}$ Thenthe ring currents were predicted using Randic model ${ }^{7}$ and the maps of currents were plotted. For instant, the currents of bonds on perimeter of anthracene were $(2 \mathrm{~N}$ for the first ring, $4 \mathrm{~N}-4$ for the mid ring, and $6 \mathrm{~N}-12$ for the last ring). And the currents of interior bonds were $(2 \mathrm{~N}-4$ for the first ring, $2 \mathrm{~N}-8$ for the mid ring, and $2 \mathrm{~N}$ 12 for the last ring). ${ }^{15}$ The obtained unnormalised currents were normalised by dividing the values by $K(K-1)$ and the results were listed in table (1).For each molecule, to obtain the scaled currents of Randić, the unnormalised currents were multiplied by a scale factor (highest value of current).

\section{RESUltS}

The ring currents were calculated using Randic model. The unnormalised ring currents were predicted and the maps of ring current were plotted Fig. 1. The maps showed that the current of bonds on perimeter of all molecules were anticlockwise (diatropic).But, the current of central inner ring of some molecules (KF9, KF16, KF17, KF18 and KF19) were paratropic (clockwise). Thus, it is expected that the aromaticity of later molecules will be less than the former molecules.

For linear catacondensed benzenoids (naphthalene, anthracene, tetracene, and pentacene), the contributions to the current of central rings were bigger than it of terminal rings. For non-linear catacondensed, the size and the shape of molecules affect the currents. Hence, the numerical values of current were increased as the number of rings increased. And the currents of catafusenes were bigger than those of perifusenes.

For some molecules; naphthalene, tetracene, triphynelene, pyrene, perylene, 3,4-benzopyrene, dibenzo [fg,op] tetracene, coronene, benzo [fg,gi] phenanthro [9,10,1,2,3-pqrst] pentaphene and quatrylene, it noticed that the ring currents of interior bonds were zero (the currents of two bonds with the same values and different directions are cancelled). For other molecules, it is also showed that the currents on periphery of catacondensed and pericondensed benzenoids were bigger than currents of interior.

Normalised ring currents of Randic were calculated by dividing the unnormalised currents by the perfect matching number $K(K-1)$, and listed in table 1 . In comparison with benzene, the results of normalization showed that benzene has the biggest value of ring current (1.000) and the minimum value of current was related to coronene (0.4421).The scaled values of ring currents were obtained by multiplying the ring current of each bond in a molecule by a scale factor. Fig. $2 \mathrm{~b}$ showed the scaled currents of anthracene.

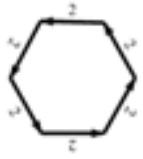

$\mathrm{KF} 1$<smiles>CC1CCCCC2CCCCCC2C1</smiles>

$\mathrm{KF} 2$

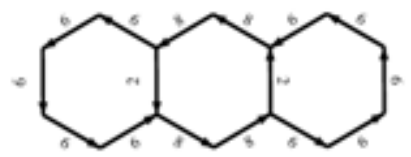

$\mathrm{KF} 3$

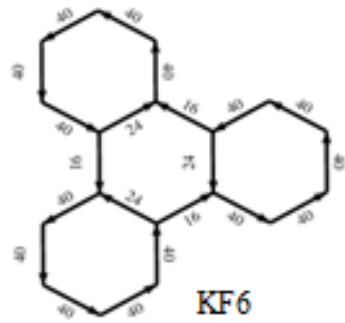

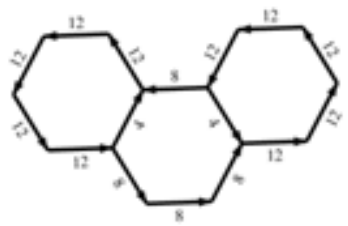

KF4

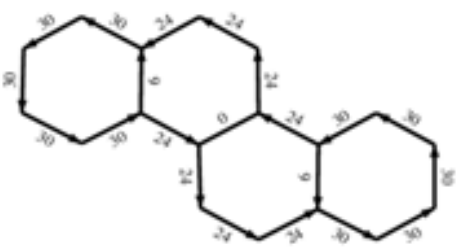

KF7 


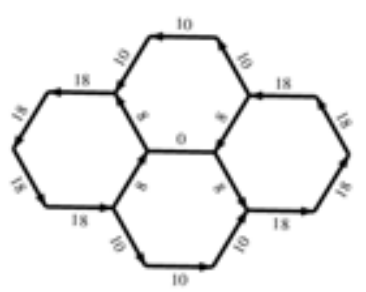

KF8

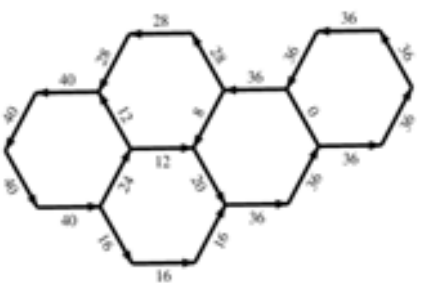

KF11

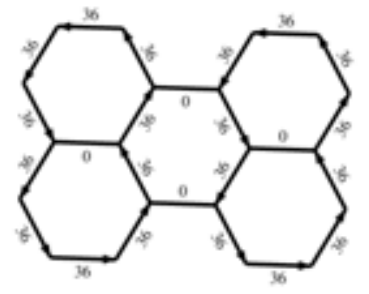

KF9<smiles>O=[WH]=O</smiles>

KF10

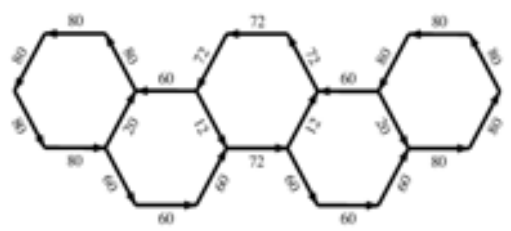

KF12

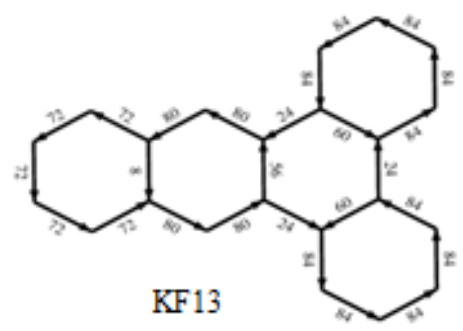

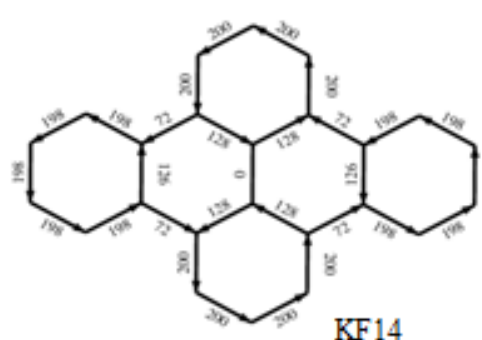

$\mathrm{KF} 14$

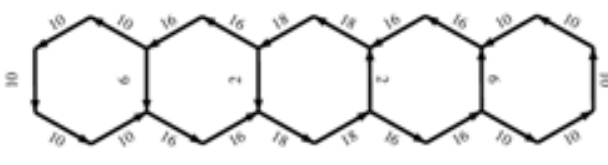

$\mathrm{KF} 15$

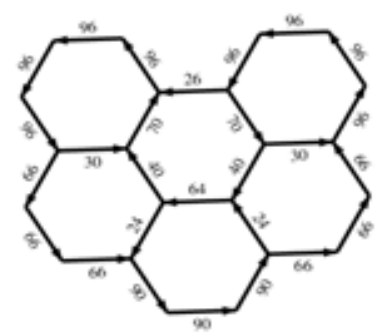

$\mathrm{KF} 16$

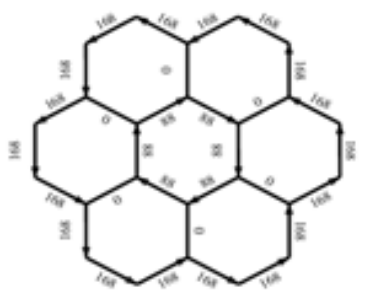

KF17

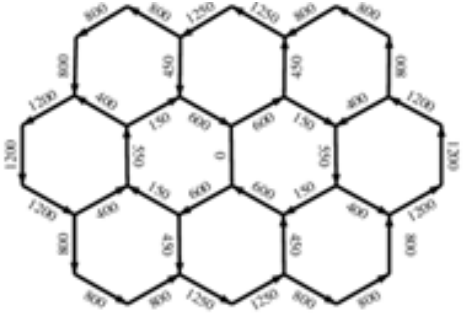

KF18

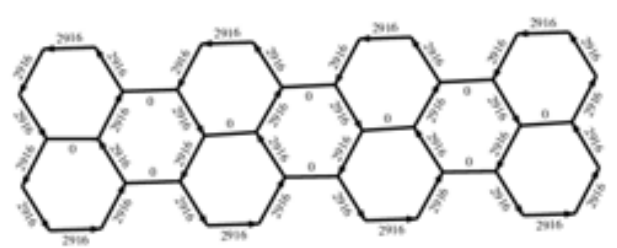

KF19

Figure1. The maps of unnormalised ring currents of the set of benzenoids calculated by Randic model

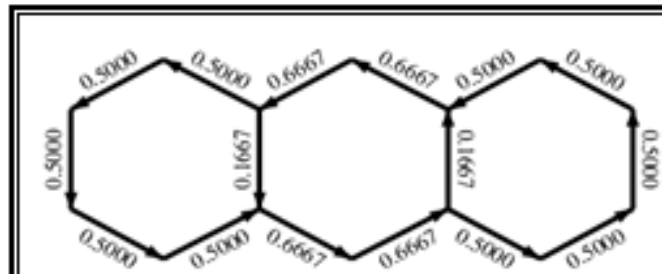

(a)

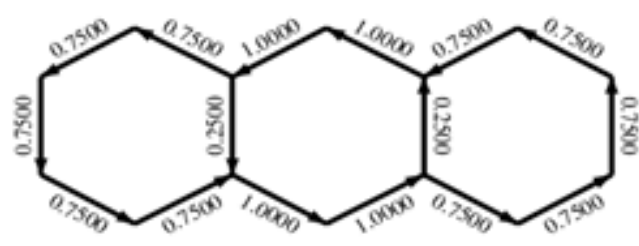

(b)

Figure2. (a) The normalised ring currentsand (b) The scaled ring currents of Randic of anthracene

Table1.The normalised currents of Randic of the set of benzenoids

\begin{tabular}{|l|c|c|}
\hline \multicolumn{1}{|c|}{ Molecules } & Symboles & The normalised currents of Randić \\
\hline benzene & KF1 & 1.0000 \\
\hline napthalene & KF2 & 0.6667 \\
\hline anthracene & KF3 & 0.5000 \\
\hline phenanthrene & KF4 & 0.6000 \\
\hline tetracene & KF5 & 0.6000 \\
\hline triphynelene & KF6 & 0.5556 \\
\hline chrysene & KF7 & 0.5357 \\
\hline
\end{tabular}




\begin{tabular}{|l|l|l|}
\hline pyrene & KF8 & 0.6000 \\
\hline perylene & KF9 & 0.5000 \\
\hline 1,2,5,6-dibenzoanthracene & KF10 & 0.5455 \\
\hline 3,4-benzopyrene & KF11 & 0.5000 \\
\hline picene & KF12 & 0.5128 \\
\hline dibenzo [a,c] anthracene & KF13 & 0.5385 \\
\hline dibenzo [fg,op] tetracene & KF14 & 0.5263 \\
\hline pentacene & KF15 & 0.6000 \\
\hline benzo [ghi] perylene & KF16 & 0.5275 \\
\hline coronene & KF17 & 0.4421 \\
\hline ovalene & KF18 & 0.5102 \\
\hline quatrylene & KF19 & 0.4500 \\
\hline
\end{tabular}

\section{CONCLUSION}

It is concluded that the Randic model of currents is a simple and useful tool to predict currents of benzenoids. It gives quantitative and qualitative maps. The plotted maps showed that all the molecules under studying are diatropic (anticlockwise). And the currents on perimeter bonds are greater than those in interior. Also it showed that the obtained values were affected by the size of molecules since the currents were increased with increasing the number hexagons. As well as, the shape of molecule affects the currents. Thus the currents of catacondensed benzenoids are greater than currents of pericondensed benzenoids.

\section{REFERENCES}

[1] L. Pauling, J. Chem. Phys., 1936, 4, 673.

[2] K. Lonsdale, Proc. R. Soc. Ser. A, 1937, 149-161.

[3] F. De Proft, P. W. Fowler, R. W. A. Havenith, P. V. R. Schleyer, G. Van Lier and P. Geerlings, Chemistry, 2004, 10, 940-950.

[4] P. W. Fowler, E. Steiner, R. W. A. Havenith and L. W. Jenneskens, Magn. Reson. Chem., 2004, 42, S68S78.

[5] M. Randić, The Open Organic Chemistry Journal, 2011, 5, 11-26.

[6] M. Randić, Chem. Rev., 2003, 103, 3492.

[7] M. Randić, A. T. Balaban and D. Plavšić, Phys. Chem. Chem. Phys., 2011, 13, 20644-8.

[8] P. W. Fowler and W. Myrvold, J. Phys. Chem. A, 2011, 115, 13191-13200.

[9] A. Soncini, P. W. Fowler, L. W. Jenneskens and S. Road, Phys. Chem. Chem. Phys., 2004, 6, 277-284.

[10] M. Randic, A. T. Balaban, Polyc. Arom. Comp, 2004, 24, 173-193.

[11] A. T. Balaban, M. Randi' c, J. Chem. Inf. Comput. Sci., 2004, 44, 50-59.

[12] A. T. Balaban, M. Randi' c, New J. Chem, 2004, 28, 800-806.

[13] R. Kiralj and M. M. C. Ferreira, j. Chem. Inf. Comput. Sci., 2002, 42, 508-523.

[14] http://www.cambridgesoft.com/ChemDraw.

[15] J. Singh, S. Singh, S. Meer, V. K. Agrawal, P. V Khadikar and T. Balaban, ARKAT, 2006, xv, 104-119.

Citation: M. Hamzah, "The Calculations of Ring Current of Some Benzenoids using Randić Model", International Journal of Advanced Research in Chemical Science (IJARCS), vol. 4, no. 7, pp. 7-10, 2017. http://dx.doi.org/10.20431/2349-0403.0407002

Copyright: () 2017 Authors. This is an open-access article distributed under the terms of the Creative Commons Attribution License, which permits unrestricted use, distribution, and reproduction in any medium, provided the original author and source are credited. 